\title{
PIBID: CONSIDERAÇÕES SOBRE O PAPEL DOS PROFESSORES DA EDUCAÇÃO BÁSICA NO PROCESSO DE INICIAÇÃO À DOCÊNCIA
}

\author{
NATALIA NEVES MACEDO DEIMLING ${ }^{1}$ \\ ORCID: http://orcid.org/0000-0001-8394-3132
}

ALINE MARIA DE MEDEIROS RODRIGUES REALI ${ }^{2}$

ORCID: http://orcid.org/0000-0003-4915-8127

\begin{abstract}
RESUMO: Neste artigo, temos por objetivo analisar de que maneira as orientações do Programa Institucional de Bolsa de Iniciação à Docência têm sido desenvolvidas e interpretadas por diferentes sujeitos na formação e atuação profissional de professores supervisores da educação básica. Para tanto, foram realizadas entrevistas semiestruturadas com 18 professores (coordenadores, colaboradores e supervisores) e 48 estudantes de quatro subprojetos do PIBID de uma universidade federal brasileira entre os anos de 2013 e 2014. Entre outros aspectos, os resultados indicam que, enquanto existem professores que tomam o PIBID como espaço de formação e de realização de um trabalho colaborativo, contribuindo para o seu desenvolvimento profissional e para a aprendizagem dos licenciandos, existem também aqueles que não se comprometem com os objetivos do Programa, não o consideram como espaço formativo e pouco contribuem com a formação dos estudantes.
\end{abstract}

Palavras-chave: Formação de Professores, Programa de Iniciação à Docência, Integração EscolaUniversidade.

\section{PIBID: CONSIDERATIONS ABOUT THE ROLE OF TEACHERS OF BASIC EDUCATION IN THE PROCESS OF INITIATION TO TEACHING}

\begin{abstract}
In this article we aim to analyze how the guidelines of the Institutional Program of Teaching Initiation Scholarship have been developed and interpreted by different subjects in the training and professional performance of teachers supervising Basic Education. For that, we conducted semistructured interviews with 18 teachers (coordinators, collaborators and supervisors) and 48 students from four PIBID subprojects of a Brazilian Federal University between 2013 and 2014. Among other aspects, the results indicate that, while there are teachers who take the PIBID as a space for training and collaborative work, contributing to their professional development and the learning of the undergraduates, there are also those who do not commit themselves to the objectives of the Program, do not consider it as a training space, and contribute little to the training of students.
\end{abstract}

Keywords: Teacher training, Teaching Initiation Program, School-University Integration.

\footnotetext{
${ }^{1}$ Universidade Tecnológica Federal do Paraná. Campo Mourão, PR, Brasil. <natanema@gmail.com>

2 Universidade Federal de São Carlos. São Carlos, SP, Brasil. < alinereali@gmail.com> Educação em Revista|Belo Horizonte|v.36|e222648|2020
} 


\title{
PIBID: CONSIDERACIONES SOBRE EL PAPEL DE LOS PROFESORES DE LA EDUCACIÓN BÁSICA EN EL PROCESO DE INICIACIÓN A LA DOCENCIA
}

\begin{abstract}
RESUMEN: En este artículo tenemos como objetivo analizar de qué manera las orientaciones del Programa Institucional de Beca de Iniciación a la Docencia han sido desarrolladas e interpretadas por diferentes sujetos en la formación y actuación profesional de profesores supervisores de la educación básica. Para tanto, realizaron entrevistas semiestructuradas con 18 profesores (coordinadores, colaboradores y supervisores) y 48 estudiantes de cuatro subproyectos de PIBID de una universidad federal brasileña entre los años de 2013 y 2014. Entre otros aspectos, los resultados indican que mientras existen profesores que toman el PIBID como espacio de formación y de realización de un trabajo colaborativo, contribuyendo para su desarrollo profesional y para el aprendizaje de los licenciandos, existen también aquellos que no se comprometen con los objetivos del Programa, no lo consideran como espacio formativo y poco contribuyen con la formación de los estudiantes.
\end{abstract}

Palabras clave: Formación de Profesores, Programa de Iniciación a la Docencia, Integración EscuelaUniversidad.

\section{INTRODUÇÃO}

O Programa Institucional de Bolsa de Iniciação à Docência (PIBID) foi disposto no âmbito do Ministério da Educação (MEC), da Coordenação de Aperfeiçoamento de Pessoal de Nível Superior (CAPES) e do Fundo Nacional de Desenvolvimento da Educação (FNDE), pela Portaria Normativa n ${ }^{\circ}$ 38, de 12 de dezembro de 2007, e regulamentado pelo Decreto $n^{\circ} 7.219$, de 24 de Junho de 2010. O PIBID concede bolsas tanto para alunos que estejam regularmente matriculados em cursos de licenciatura como para coordenadores e supervisores responsáveis pelo desenvolvimento do projeto, com auxílios para despesas a eles vinculadas.

Em 2014, 284 Instituições de Educação Superior de todo o País participavam do PIBID desenvolvendo 313 projetos de iniciação à docência em mais de 5 mil escolas públicas de educação básica, e, em 2016, o número de bolsas ativas no Programa alcançou o total de 72.057, distribuídas entre estudantes de licenciatura, professores da educação básica e professores do ensino superior. Recentemente, o PIBID passou por uma reformulação, tendo sido regulamentado pela Portaria $\mathrm{Gab}^{\circ}{ }^{\circ}$ 45, de 12 de março de 2018 (BRASIL, 2018), em regime de colaboração, juntamente com o Programa de Residência Pedagógica - outro programa de complementação de formação proposta pelo MEC para os cursos de licenciatura. A partir dessa reformulação, foram reduzidas para o máximo de 45 mil as bolsas na modalidade de iniciação à docência oferecidas para todo o Brasil.

De acordo com o Decreto 7.219/2010, o PIBID tem como objetivos, entre outros aspectos, "incentivar escolas públicas de educação básica, mobilizando seus professores como coformadores dos futuros docentes e tornando-os protagonistas nos processos de formação inicial para o magistério" (BRASIL, 2010, p. 4). Apesar de o Programa se configurar como uma das soluções emergenciais acionadas pelo Governo Federal para tentar suprir a carência de professores da educação básica e manter os estudantes nas licenciaturas, não podemos desconsiderar a importância de algumas de suas metas traçadas e suas possibilidades de viabilização em termos de formação docente. Considerando esses aspectos, objetivamos, neste artigo, apresentar uma análise sobre as influências do PIBID na formação e na atuação profissional de professores. Neste caso particular, dissertaremos sobre os professores supervisores da educação básica, bem como sobre o papel desses profissionais no processo de iniciação à docência, tendo como base os dispositivos legais que fundamentam o Programa e alguns dos estudos que têm formulado ideias e análises sobre a formação e a atuação docentes.

Trata-se de uma das categorias de análise discutidas em uma pesquisa científica de abordagem qualitativa, que teve na análise documental e na entrevista semiestruturada os principais 
instrumentos de construção dos dados; e na triangulação e criação de categorias, os instrumentos de análise desses dados (LÜDKE; ANDRÉ, 2013). Tendo em vista entender como os diferentes sujeitos envolvidos compreendem e avaliam o PIBID no âmbito da formação e atuação profissional dos professores da educação básica, foram realizadas entrevistas: com 1 coordenador institucional; 2 coordenadores de área de gestão de processos educacionais; 4 coordenadores de área; 4 professores colaboradores; 7 professores supervisores; e 48 alunos bolsistas de 4 subprojetos do PIBID de uma universidade federal brasileira durante os anos de 2013 e 2014. Os subprojetos em questão estão vinculados a quatro cursos distintos: Licenciatura em Física, Licenciatura em Letras-Português/Inglês, Licenciatura em Matemática e Licenciatura em Química .

A análise e a discussão dos dados respaldam-se em estudos realizados por relevantes trabalhos que discutem sobre a formação docente, bem como sobre as bases legais que regulamentam e dispõem sobre o PIBID e a interpretação que os sujeitos que participam desse Programa fazem sobre suas contribuições, limitações, desafios e influências, neste caso específico, na formação e atuação dos professores supervisores da educação básica no processo de iniciação à docência.

Por questões éticas, os quatro subprojetos do PIBID analisados neste estudo foram denominados A, B, C e D, aleatoriamente. Além disso, os nomes dos participantes e de pessoas citadas por eles foram ocultados e, quando necessário, substituídos por nomes fictícios. Da mesma forma, os nomes dos cursos/disciplinas específicos foram substituídos nos excertos pelo termo conteúdo específico, seguido da letra que indica o subprojeto. Ademais, para diferenciar os relatos dos sujeitos que participaram do estudo, foram utilizadas algumas siglas: Coordenador de Área de Gestão de Processos Educacionais (CG), Coordenador de Área (CA), Supervisores (S), Colaboradores (C) e Bolsistas de Iniciação à Docência (B). Assim, no fim de cada relato, é apresentada entre parênteses a sigla que corresponde ao subprojeto analisado, seguida da sigla correspondente ao sujeito narrador.

\section{O PAPEL DOS PROFESSORES DA EDUCAÇÃO BÁSICA NO PROCESSO DE INICIAÇÃO À DOCÊNCIA}

Diferentes estudos que discutem sobre a formação de professores (MIZUKAMI, et al., 2002; SHULMAN, 2005; GARCÍA; VAILLANT, 2009; ZEICHNER, 2010; TARDIF, 2012, entre outros) têm defendido que as experiências práticas, aliadas aos saberes científicos e acadêmicos, se constituem em importantes ocasiões para que se efetive a aprendizagem docente. Essa articulação entre teoria e prática na formação de professores, tão defendida e enfatizada pela literatura, pode ser favorecida, também, pelo PIBID; ele objetiva, entre outros aspectos, articular a formação acadêmica dos licenciandos ao saber proveniente do conhecimento e da experiência dos professores das escolas e das universidades. Trata-se de um espaço de formação tanto para licenciandos quanto para os professores da educação básica e do ensino superior.

Um dos objetivos traçados pelo PIBID refere-se à participação dos professores da educação básica na formação dos licenciandos, futuros professores. Essa participação pode contribuir tanto para a formação dos estudantes quanto para a formação dos professores supervisores, uma vez que, ao agirem na formação dos alunos, estes últimos têm a oportunidade de analisar e modificar suas concepções e também suas práticas, tornando-se autônomos, sensíveis e atentos à complexidade do espaço em que estão inseridos. Nesse processo, ambos, professor e aluno, aprendem. Além disso, ao atuarem como coformadores de futuros professores, esses profissionais são também reconhecidos pela universidade, o que pode favorecer ainda mais a aproximação entre o ensino superior e a educação básica e a articulação entre conhecimento científico e os saberes práticos.

Segundo García (2010), muitos programas de inserção ao ensino desenvolvidos em diferentes países têm incluído a figura do professor experiente na formação dos futuros professores ou de professores iniciantes. Para o autor, esse profissional desempenha um papel de grande importância nesses projetos de formação, pois é a pessoa que ajuda, dá orientações e integra o licenciando ou professor em início de carreira na cultura escolar. 
Em muitas situações, o corpo docente da educação básica é desvalorizado em relação aos saberes que possui. Todavia, esses professores têm uma função social estrategicamente tão importante quanto à da comunidade científica e dos grupos considerados produtores de saberes. Seria de se esperar, assim, que ocorresse um certo prestígio e reconhecimento social positivo do papel desempenhado também por esses profissionais no processo de produção dos saberes sociais (TARDIF, 2012), bem como dos conhecimentos sobre a prática que eles constroem. Uma vez que o PIBID objetiva colocar os professores da educação básica como coprotagonistas na formação inicial dos licenciandos, sinaliza-se o reconhecimento do papel desses profissionais e de seus saberes, alguns dos quais adquiridos pela experiência.

Além disso, o contato dos estudantes com os saberes e práticas dos professores da educação básica pode favorecer, ainda, uma articulação entre as políticas educacionais e as necessidades e demandas apresentadas pela realidade escolar e seus profissionais - um dos aspectos apontados como necessários por associações de educadores e pesquisadores para a elaboração de uma política global de formação docente. Conforme aponta Libâneo (2005), não é possível resolver a questão das políticas de formação sem encarar os interesses, as necessidades e as dificuldades encontradas dentro da própria escola e, numa perspectiva mais ampla, dentro da própria sociedade. Daí a importância desse contato da universidade e dos licenciandos com a realidade escolar para o processo de formação docente.

Frequentemente, as necessidades e demandas da realidade escolar não são consideradas quando da elaboração e regulação de políticas e programas educacionais e, especialmente, de formação docente. Em muitos casos, o professor, especialmente da educação básica, é visto como um "consumidor de reformas" desenhadas pelas elites nacionais ou, em alguns casos, importadas de outros países. Ao longo dos anos 1990 e início da década de 2000, foi promovida uma intensa reforma educacional desenhada por administrações internacionais e nacionais convencidas de que a melhoria na qualidade da educação dependia sobremaneira da formação de seus profissionais. Nessa perspectiva, traduzia-se uma visão do docente como o responsável pelas mazelas do ensino e como aplicador "automático" de inovações que, com frequência, nem sequer entende, e em cuja formulação, certamente, não teve participação alguma. Essa visão do docente e dos processos de formação, ao mesmo tempo que desconhece e desconsidera a realidade e as condições sociais e históricas que geram essa situação, deprecia a prática profissional docente e considera que as mudanças na educação são processos lineares que se implantam de forma simples, contanto que saibamos "explicar" bem aos docentes em que consistem (GARCÍA, 2010).

Todavia, como aponta García (2010), os processos de mudança, tanto nos indivíduos quanto nas organizações, não funcionam de maneira puramente racional. Para o autor, os sistemas complexos geram seus próprios processos de autorregulação para se acomodarem ou modificarem as propostas de mudança, que nem sempre têm os resultados previstos pelas instâncias promotoras. Por isso, há a necessidade de programas que se relacionem diretamente com as necessidades e demandas escolares e que reconheçam o professor como sujeito dessa formação. Nesse sentido, o PIBID, ao dar ao professor da educação básica o status de coformador de futuros professores - o que sugere sua participação ativa , poderia contribuir para a superação desse modelo de formação que visa apenas "atualizar" o professor da educação básica e torná-lo mero executor de um processo ao qual esteve completamente alheio.

Em um trabalho que discute a importância da prática na formação do professor, Nóvoa (2009) defende justamente que a formação de professores deve assumir uma componente prática que leve em consideração o estudo de casos concretos, tendo como referência, também, o trabalho escolar e os saberes dos professores mais experientes. Para o autor, a formação docente deve compreender, entre outros aspectos, o contato com a instituição escolar e o aprendizado com seus profissionais, já que é também no contato com a escola e no diálogo com os outros professores que se constitui a profissão docente. Logo, as práticas profissionais, assim como a formação científica, seriam transformadas em conhecimento e instituídas como elementos de formação.

Todavia, é importante que essa inserção dos licenciandos no meio das práticas docentes e seu contato com professores experientes da educação básica e superior não contribuam apenas para a compreensão de casos didático-pedagógicos ou para a "criação e participação em experiências metodológicas, tecnológicas e práticas docentes de caráter inovador” (BRASIL, 2010, p. 4), como propõe 
o PIBID. Devem contribuir, principalmente, para discussões sobre as questões sociais que fazem emergir as condições sob as quais essas experiências se realizam. Trata-se de questões que afetam diretamente a formação e a atuação docente, tais como aquelas relacionadas à relevância e ao papel social do professor, à valorização da carreira docente, às condições concretas e objetivas de trabalho, ao financiamento da educação, às políticas públicas de educação básica e suas intencionalidades, à relação entre a escola e a comunidade e entre a comunidade e o Estado, às concepções e fundamentos de educação que permeiam os programas e a organização do ensino, ao papel da gestão escolar, entre outros aspectos.

Da mesma forma, a incorporação de saberes práticos não pode se dar de forma acrítica e descontextualizada. Pelo contrário: é necessário que se estabeleçam os reais vínculos entre a prática e as condições sócio-históricas em que se situa. A inserção do estudante de licenciatura na cultura escolar e seu contato com professores já em exercício contribuem para sua formação na medida em que proporcionam não a sua adaptação ao sistema ou às práticas desses professores, mas a sua capacidade de análise do que está posto, tendo como base o conhecimento adquirido na universidade; conhecimento este produzido ao longo da história por teóricos e estudiosos dos diferentes campos do conhecimento, que visam discutir as relações de poder e de interesse que permeiam e determinam as ações educativas. A ausência dessa análise pode levar à pura e simples imitação acrítica de condutas observadas, ao desenvolvimento de uma concepção técnica do ensino, a uma compreensão parcial do processo educativo e, consequentemente, a uma alienação sobre o trabalho. Concordamos com Nóvoa (2009) quando ele afirma a necessidade de uma formação que contemple também o processo histórico da profissão docente, seus determinantes sociais e políticos, bem como a análise do conhecimento e do processo educativo em suas diferentes dimensões. O contato dos estudantes com a realidade escolar pode contribuir de maneira significativa para essa compreensão global e dimensional da educação e da profissão docente, ainda no momento da formação inicial.

Compondo esse processo de formação de futuros professores, o PIBID recomenda, ainda, que o trabalho seja realizado de forma coletiva. Esse trabalho seria desenvolvido, como se propõe, entre os professores experientes - da universidade e da escola - e alunos bolsistas de iniciação à docência de um mesmo subprojeto não numa relação hierárquica (em que, por exemplo, os conhecimentos acadêmicos se sobrepõem aos conhecimentos escolares e práticos), mas numa relação colaborativa, o que favoreceria, novamente, a aproximação entre os centros de formação e as escolas, objetivo do Programa. Essa necessidade de trabalho coletivo é reforçada também por alguns autores que discutem sobre o tema. Um deles é Nóvoa (2009), que aponta a necessidade de um reforço das dimensões coletivas e colaborativas no trabalho escolar e da intervenção conjunta nos projetos educativos, tanto para a realização do trabalho escolar quanto para o desenvolvimento profissional dos professores. Segundo o autor, a escola deve se configurar como um espaço de análise partilhada de práticas docentes, transformando a experiência coletiva em conhecimento profissional.

Considerando tais aspectos, o trabalho coletivo pode, também, contribuir para a superação ou minimização do isolamento que caracteriza o trabalho do professor na escola. De acordo com García (2010), existe um grande paradoxo na profissão docente: enquanto a literatura expõe a necessidade de os professores colaborarem e trabalharem conjuntamente, temos uma realidade de docentes que se refugiam na solidão de suas salas de aula. Para o autor, existe um grande individualismo no trabalho dos professores, sendo este ocasionado, também, pela própria organização e arquitetura escolar em sua distribuição de espaço e de tempo, o que coloca as interações entre os professores à margem de seu trabalho diário. García (2010, p. 16) argumenta, ainda, que o isolamento docente possui certas vantagens e alguns evidentes inconvenientes para os professores, pois, embora facilite o trabalho individual e libere os professores de algumas das dificuldades associadas ao trabalho compartilhado, também os "priva da estimulação do trabalho pelos companheiros e da possibilidade de receber o apoio necessário para progredir ao longo da carreira". Por esse motivo, o autor defende o trabalho coletivo e colaborativo entre os professores, a fim de que possam, nesse trabalho, reconhecer suas dificuldades, pedir ajuda quando necessário e aprender também com seus pares, convertendo, assim, a própria experiência individual em experiência coletiva.

Feita a análise interna de alguns dos objetivos e dimensões do PIBID - a partir de estudos que tratam sobre a formação e atuação docente e sobre o papel do professor experiente na formação 
docente -, cabe-nos analisar se eles têm sido atendidos não apenas em termos formais, mas também em termos reais, sem deixar de considerar, todavia, o fato de que as políticas, quando postas em prática, são modificadas pelas condições e contextos em que se desenvolvem. Para a realização dessa análise, faz-se necessário conhecer também o que os sujeitos envolvidos no processo pensam sobre o Programa e como o interpretam e o concebem em seu aspecto formativo.

\section{O PIBID E SUAS INFLUÊNCIAS NA FORMAÇÃO E ATUAÇÃO PROFISSIONAL DE PROFESSORES DA EDUCAÇÃO BÁSICA}

Todos os professores supervisores entrevistados em nosso estudo possuem mais de dez anos de experiência na educação básica e formação na disciplina em que lecionam. Esse fato, certamente, contribui de maneira mais sólida para sua atuação enquanto coformadores no processo de discussão, planejamento, desenvolvimento e avaliação das ações no âmbito do PIBID. A propósito, a presença e a participação desses supervisores no planejamento e desenvolvimento das atividades do Programa são essenciais não apenas para a formação dos bolsistas de iniciação à docência, mas, igualmente, para sua própria formação e contato com o espaço universitário. De acordo com dados das entrevistas, o PIBID tem também contribuído para aproximar alguns professores da educação básica desse contexto, e incentivado-os a dar continuidade em sua formação, como podemos observar nas narrativas do coordenador institucional e de dois coordenadores de área:

E outra, você aproxima o supervisor e a escola da universidade, também é uma coisa interessante, então eles acabam vendo que a universidade não é aquele olimpo que está lá em cima, é inacessivel. Não, todo mundo é colega professor, e eles acabam interagindo e se interessando pela universidade também. Um exemplo que eu posso dar [...] é que nós temos dois coordenadores de PIBID [professores supervisores] que estão fazendo mestrado com a gente, entende? [...] Necessariamente os projetos deles não são do PIBID, isso ainda me dói, porque eu acho que teria que ter mais coisas, mas mesmo assim eles surgiram porque eles eram supervisores do PIBID e eles viram a necessidade formativa, entende? Então o PIBID é uma grande ponte assim (CI, grifos nossos).

Outra coisa que eu percebo, assim, já tem uma professora supervisora, ela está pensando em fazer um mestrado e ela quer ver qual universidade, porque a universidade ela tem um mestrado na área de educação. Então isso daí também despertou neles a vontade de continuar estudando, voltar a estudar. $\mathrm{O}$ outro professor, além de se envolver muito com o PIBID, eu percebi que ele gostou muito de se envolver com o PIBID, ele já se propôs de ver se teria um tempo melhor para poder vir aqui a tarde para ajudar, de ele vir aqui a tarde para poder ajudar o grupo porque ele dá aula manhã e noite, então ele falou "eu tenho as tardes que dá para vir aqui" (BCA, grifos nossos).

Como podemos observar nos relatos, existe uma ideia comum entre os entrevistados de que a aproximação que o PIBID proporciona entre universidade e escola não influencia apenas a formação dos bolsistas de iniciação à docência, mas, em semelhante importância, a formação dos demais envolvidos no Programa, em especial a dos professores supervisores da educação básica. Tal ideia pode também ser identificada nas narrativas de dois coordenadores de área, um professor colaborador e um bolsista de iniciação à docência:

Eu acho que é importante o professor vir pra universidade, então, ver o que tem aqui na universidade que a gente pode levar pra escola, o que tem na escola que a gente pode trazer pra universidade, eu acho que é essa questão então de estreitar os laços existentes e desmistificar esse dentro-fora da escola, mas acho que essa é uma das coisas que ainda precisa ser melhor trabalhada e desenvolvida. A formação do professor deve ocorrer nesses dois espaços. Então, nós formarmos nosso futuro professor quanto trabalharmos a formação daquele que já é professor... isso é muito importante (BC, grifos nossos).

Principalmente um deles [professor supervisor] teve uma grande mudança... Ele foi o que eu mais senti uma mudança na prática dele... Ele, e segundo, o [outro professor supervisor], que também é o quarto professor supervisor. Ele incorporou as atividades do PIBID que nós desenvolvemos na aula dele e mesmo que os alunos não estejam lá pra desenvolver aquela prática... Ele desenvolve, ele pega aquela 
prática, ele modifica e ele continua fazendo. Ele faz isso, o [outro professor supervisor] faz isso e os outros dois não, mas eles vieram fazer o mestrado aqui. Então, quer dizer, é uma mudança... Também os outros dois estão numa escola que já mais difícil de ter mudanças [escola central/modelo]. As outras escolas são mais abertas. Também tem isso, da escola ter essa receptividade (ACA, grifos nossos).

É também possível observar a influência do PIBID na formação dos professores supervisores em suas próprias narrativas. Quando questionados sobre as contribuições do Programa para sua formação e atuação profissional, alguns relataram:

Total, total, porque eu não me distanciei do ensino superior, do ensino acadêmico, da pesquisa. Não me distanciei de técnicas de aprendizado, de técnicas de ensino, do próprio aluno acadêmico. Eu acho que eu não me distanciei deles e eles traz̧em essas ideias mesmo [...]. Então com eles eu mantenho a ponte da novidade também. $\mathrm{E}$ da novidade à necessidade. E com os adolescentes mais ainda. E com a coordenação mais ainda porque ela tem mais experiência ainda e bem acadêmica, um pós-doc. Então tudo isso aqui pra mim é fonte assim de conhecimento, conbecimento, conbecimento (CS, grifos nossos).

Nossa, demais. Fazia tanto tempo que eu não me ocupava com coisas diferentes. E aqui, a gente, nossa, no começo a gente faz̧ia muita leitura, texto, o [coordenador de área] trazia textos pra gente, livros, então, de uma certa forma, isso ai a gente acaba aprendendo. Então os textos que ele trazia, pra gente ler de vez em quando ajudaram bastante (DS, grifos nossos).

Que nem com o estagiário a gente tem feito bastante, eu acredito que toda nossa... mudou muito assim. Eu digo pela minha prática do ano passado para a minha prática desse ano em sala de aula, en falei, esse ano eu dei aula, eu me vi sabe? (BS, grifos nossos).

A partir dos relatos, podemos afirmar que o PIBID tem influenciado de maneira positiva a formação dos supervisores entrevistados, possibilitando-lhes o contato com o ambiente universitário e seus profissionais e, como consequência, a análise de sua prática a partir de discussões e reflexões de cunho teórico e acadêmico. Este é também um dos aspectos discutidos no estudo realizado por Gatti et al. (2014) e nas pesquisas de Paredes (2012), Stanzani (2012) e Moura (2013), segundo os quais o PIBID favorece em grande medida a formação continuada dos supervisores por meio de sua aproximação com a universidade, seus saberes, profissionais e estudantes.

Desta maneira, é possível inferir que as ações que têm sido realizadas pelos supervisores na formação dos bolsistas têm desencadeado, em certa medida, uma mudança em sua própria atuação profissional. Tal afirmação vai ao encontro das discussões realizadas por Tardif (2012), o qual, tendo como base algumas das ideias defendidas por Marx, afirma que toda práxis social é, de certa forma, um trabalho cujo processo de realização desencadeia uma transformação real no trabalhador. Trabalhar, portanto, não significa exclusivamente transformar um objeto ou situação numa outra coisa, mas, igualmente, transformar a si mesmo no e pelo trabalho. Assim, no momento em que o professor da educação básica atua na formação do licenciando ele está, simultaneamente, atuando em sua formação e modificando sua prática.

Tendo sua formação e seu trabalho enriquecidos, alguns dos professores supervisores tendem a se envolver no Programa e a atuar efetivamente como coformadores dos estudantes da licenciatura, por meio da discussão e elaboração, com eles e com os demais envolvidos no projeto, de ideias e atividades que visam contribuir para a formação e a prática docente. Embora, segundo alguns dos participantes entrevistados, haja momentos de conflito nesse processo de discussão e planejamento das atividades - com sobreposição, em alguns casos, da ideia advinda da universidade (bolsistas de iniciação à docência, coordenadores de área e colaboradores) ou da escola (professores supervisores) -, de maneira geral, tal processo ocorre de modo colaborativo, como é possível observar nos relatos de alguns alunos bolsistas e coordenadores de área:

Agora o [professor supervisor] é diferente, ele ajuda, ele palpita, ele diz que, ele traz as coisas, sabe, se estiver precisando. Ele dá ideia, ele ajuda bastante o grupo. E até na hora da intervenção ele está sempre pra ajudar, porque geralmente a gente tem, é em grupo de três pessoas, geralmente a gente separa eles [alunos da educação básica] por grupos menores, então ele sempre está junto. "Olha, vamos 
fazer assim". Então realmente, o nosso, agora supervisor, não tem o que reclamar, ele dá ideia, ajuda ( $\mathrm{AB}$, grifos nossos).

A professora [supervisora] é totalmente diferente. Depois da primeira ela falou: "ah meninas, vocês podem trabalhar", levou livros pra gente sobre o assunto de gêneros, exatamente o que nós pretendemos trabalhar, e levou outros materiais que nós não tínhamos acesso pra que nós pudéssemos melhorar a aula e eu acho isso muito interessante, porque nunca vi uma professora fazer isso ( $\mathrm{CB}$, grifos nossos).

Então, às vezes ela acaba trazendo o conteúdo, tipo, "seria legal trabalhar alguma coisa com isso." Eles, assim, sempre perguntam, em questão de experiência, alguma coisa assim, eles sempre perguntam. [...] Ele sempre está disponivel e sempre ajuda a gente (BB, grifos nossos).

Eles participam, a gente faz assim, eles pegam hora a atividade do professor, e vão naquele dia, eles acompanham a atividade do professor, e na hora da atividade eles sentam para fazer planejamento com o professor. E esse momento da hora atividade do professor, eles sentam e pensam juntos (ACA, grifos nossos).

Pelos relatos que ela [supervisora] me faz e pelos relatos que os alunos estão fazendo, ela, às vezes ela está explicando e aí para e diz.pros alunos, "olha estou fazendo isso por isso e por isso e aquilo". Ela dá aula pros alunos e pros alunos do PIBID ali. E, às vezes, nas outras turmas ela me disse que, ela chama atenção antes e deixa que eles aí conduzam uma certa atividade. Depois ela tem um tempinho depois da aula e ela comenta com eles. Então, eu acho que está dando certo. [...] Ela também participa, ela sugere materiais, ela tem conbecimento e tem dado sugestôes (CCA, grifos nossos).

De fato, considerando os objetivos do PIBID, a participação ativa dos professores supervisores torna-se essencial para a formação dos envolvidos e para a discussão e desenvolvimento das atividades e práticas realizadas. Outrossim, é importante que essa participação ocorra numa perspectiva colaborativa de modo que todos - professores das escolas, professores universitários e estudantes em formação -, possam discutir em conjunto as atividades e objetivos propostos. Essa também é uma das ideias defendidas por alguns estudos e pesquisas que têm o PIBID como foco. Temos como exemplo as pesquisas de Dorneles (2011), Gaffuri (2012) e Afonso (2013) e o estudo de Gatti et al. (2014), os quais, a partir de seus resultados, afirmam que o trabalho colaborativo proporcionado pelo PIBID possibilita, entre outros aspectos, o diálogo, a problematização e o compartilhamento de saberes e experiências da docência entre professores experientes do ensino básico, licenciandos e professores universitários.

Muitos dos estudos que têm como foco a formação de professores (MIZUKAMI et al., 2002; REALI et al., 2005; REALI; TANCREDI, 2005; DAMIANI, 2008; NÓVOA, 2009; GARCÍA, 2010; ZEICHNER, 2010) mostram que a parceria entre as universidades e as escolas se configura como um espaço fecundo para trabalhos em colaboração com os professores e não apenas para os professores. Nessa perspectiva, os grupos ou encontros de discussão e estudos são utilizados como um espaço privilegiado para o conhecimento da realidade dos que atuam, pensam e fazem o ensino na escola - bem como para a troca de ideias e de experiências, saberes e práticas entre os diferentes sujeitos que participam desses momentos de formação - no qual todos se reúnem movidos pela necessidade da visão e conhecimento do outro para a constituição de sua própria formação.

Segundo Mizukami et al. (2002), nessa perspectiva de trabalho, os saberes não devem ser construídos de forma isolada, mas em parceria entre pessoas que estão em diferentes níveis de desenvolvimento profissional, como é o caso, por exemplo, do PIBID. Nele, os sujeitos envolvidos encontram-se em diferentes momentos de formação e de atuação profissional, e é justamente essa diferença que, em alguns casos, tem enriquecido o trabalho colaborativo e a análise dos trabalhos desenvolvidos no âmbito do Projeto. Para Tardif (2012), tais relações e interações apresentam-se, também, como uma oportunidade para que os professores, juntamente com os demais atores, elaborem e reelaborem seus saberes teóricos e experienciais no campo de sua prática, o que também contribui, como consequência, para a constituição e o desenvolvimento de sua própria formação.

Todavia, mesmo o Programa sendo reconhecido como um campo de possibilidades de formação pelos supervisores entrevistados, e mesmo considerando o fato de alguns deles estarem atuando de maneira positiva na formação dos estudantes das licenciaturas e desenvolvendo com a 
universidade um trabalho colaborativo, grande parte dos participantes do estudo - entre coordenadores e alunos bolsistas - afirmaram que há supervisores que atuam ou que já atuaram no Programa que não compreendem os objetivos do PIBID; como consequência, não se envolvem com o Projeto e não o tomam como espaço e oportunidade de formação e de análise sobre a prática. Tal afirmação pode ser ilustrada, por exemplo, nos relatos provenientes das entrevistas com os coordenadores (institucional, de gestão e de área) participantes deste estudo:

Mas também existem relatos, recordando, eu tenho para mim que a relação com o supervisor não muito é boa. Que o supervisor que entra com a visão tradicional e não colabora e não tem esse perfil, ele acaba não conseguindo ficar no PIBID, entendeu? [...] Ele acaba entrando em confronto com os alunos, com os acadêmicos que vão para lá e acaba não estabelecendo uma relação. Daí o que acontece, a gente tem muita mudança de supervisor [...]. E como eu sei disso? Eu interajo no sistema, sou eu que, a pedido dos coordenadores, coloco e depois tiro, entende? E daí eu tenho que justificar para a CAPES, e as justificativas geralmente são essas, "supervisor não colabora com os objetivos do PIBID”. Tem muita rotatividade de supervisores, sabe? Eu tive cada caso, você não acredita. Eu já vi supervisor que queria ficar com duas bolsas, umas coisas assim absurdas, mas são coisas inerentes ao ser humano. Assim como tem o ser humano extremamente proativo tem aquele que não. E tem uma coisa interessante, o dinheiro é muito bom para o supervisor, dá quase um padrão do estado, então realmente às vezes ele vai pelos motivos errados, ele vai pelo dinheiro e tal, dai quando ele vê a relação de trabalho, ele é uma pessoa assim de cunbo mais tradicional, dai ele não contribui, entende? (CI, grifos nossos).

Então nesse começo a dificuldade era essa, o professor que dizia "não, eu vou, eu faço", tudo bem, e ai depois não vinha participar de nenhuma reunião aqui na instituição [...] não queriam participar, nunca podia, nunca podia, nunca podia, e quando o aluno do PIBID ia pra escola, ele não estava, porque tinha aquela coisa, "ah mas vai ter estagiário na minha sala, eu não preciso vir". E não é isso, professor tem que estar na sala de aula, atender os alunos no corredor e tal, então teve isso, e por outro lado, a bolsa de $\mathrm{R} \$ 750,00$ é pouco, mas é quase um padrão, não é? [...] Então ao mesmo tempo em que chama atenção, exige bastante. Então nós tivemos isso, escolas em que ninguém queria participar, e depois escolas que alguns queriam participar, mas não se comprometiam a fazer o mínimo que seria necessário (CG, grifos nossos).

Eu tenho um professor supervisor que ele acha que bastava abrir as portas da sala de aula e deixar os alunos entrarem, fazer atividade e sair, ele não se envolve. [...] Eu já tentei, já fui lá, já assisti as aulas dele, fiz o planejamento, mas é dele, é da natureza dele, ele não aceita que haja interferência na prática pedagógica dele. É um professor que não é aberto para modificaşoes, ele não pode ser supervisor do PIBID, então infelizmente, porque assim, ele teve muita boa vontade em nos receber. Mas infelizmente ele não coopera, ele não colabora, e o supervisor ele tem que ser aberto, não é? [...] Eu vejo porque eu estou lá, eu vou junto. Eu vejo, e ele sai, eu vou atrás dele, "ah é que eu fui chamado, eu já volto, que eu fui chamado lá na direção", ele some. E aí fico eu com os alunos na sala dele, e isso não dá segurança para os alunos desenvolverem atividade na aula. Aí quando ele volta os alunos já aplicaram atividade, ele não viu, ele não participou, então realmente é muito difícil. Olha, eu acho que o maior problema dos PIBIDs que eu tenho visto, pelo que eu tenho conversado com os meus colegas coordenadores, é você encontrar supervisores que estejam vinculados e que abracem mesmo a causa desse tipo de trabalho. É raro você achar. [...] Eles ficam, eles veem a bolsa, a bolsa perante o salário deles ela é muito boa, ela ajuda muito, então eles querem ganhar a bolsa, mas eles não querem se comprometer com os termos de compromisso básico que eles assumiram. Ainda a minha grande crítica são os professores supervisores, é uma oportunidade ótima de aproximação nossa e que muitos não aceitam, infelizmente (ACA, grifos nossos).

Era uma pessoa que se mostrou muito aberta no inicio, mas que depois parece não ter entendido exatamente o que era o projeto. Teve dificuldades de relacionamento com certos alunos. A direção também da escola me parece que priorizou muito o trabalho com [outro subprojeto]. [...] Então, esse também foi o motivo de troca de escola. [...] Existem alguns professores supervisores que infelizmente eles acham, parece que o aluno está lá pra quebrar um galho. Então, não posso agora e você faz? O professor também precisava ter mais responsabilidade, sabe? É tão fácil ganhar $\mathrm{R} \$ 700,00, \mathrm{R} \$ 750,00$ pra, tudo bem, mas se você for pensar que for um trabalho bem feito é pouco. Você tem 10 pessoas pra coordenar, organizar na escola, chamar e tal e tal. Agora quando eles só recebem e não... aí é complicado (CCA, grifos nossos).

O que eu percebo que não é bom, mas que eu estou tentando corrigir também, é que elas não se sentem muito a vontade com os alunos entrando nas aulas delas. Então eu peço pra que elas permitam que 
os alunos participem das aulas como ouvintes ou até como alguém fazendo observação participante. Sei que algumas fazem isso, mas elas também deixam atividades pra eles fazerem fora da sala de aula porque elas se sentem mais à vontade, eu acredito. Então vamos dizer assim, que elas tão deixando os alunos entrar na sala, mas se eu queria 100\%, elas estão fazendo $30 \%, 40 \%$ e o restante das atividades eles ficam do lado de fora ou ajudando alguns alunos com algumas atividades ou lendo documentos da escola, regimento, essas coisas todas, elas sempre têm uma atividade para os alunos, mas nem sempre é o que eu gostaria que fosse (DCA, grifos nossos).

Como podemos observar, muitos dos professores da educação básica que se propõem a acompanhar e orientar a inserção dos estudantes da licenciatura nas escolas não têm assumido essa responsabilidade na prática. Segundo os coordenadores entrevistados, no seu contexto, muitos desses profissionais têm ingressado no PIBID apenas pela oportunidade de receber um auxílio financeiro e, também por esse motivo, deixam de se envolver no projeto e de desenvolver um trabalho colaborativo que contribua, de fato, tanto para a formação dos alunos bolsistas quanto para sua própria formação e atuação profissional. Com isso, tem ocorrido grande rotatividade de supervisores, o que, de certa maneira, acaba prejudicando o andamento das atividades e dos objetivos propostos pelo Programa para a formação dos envolvidos.

Tais aspectos podem também ser evidenciados por muitos dos relatos apresentados pelos bolsistas de iniciação à docência em suas entrevistas, segundo os quais alguns dos professores supervisores que atuam nos subprojetos não compreendem os objetivos do PIBID e, por esse motivo, não modificam suas práticas e não colaboram de forma efetiva em sua inserção e formação nas escolas. Dentre os relatos apresentados, podemos destacar: Até agora que a gente mudou de área, a gente estava no [escola de centro] com um supervisor,
só que a gente tinha um problema com ele, não sei se ele era muito atarefado, mas ele não
participava tanto do projeto, então, ele cedia aula quando precisava pra gente fažer alguma intervenção, só que ele
não dava nenhuma sugestão, ele não participava, ele não opinava, porque reunião aqui ele não vinha (AB,
grifos nossos).

Já é um ano lá, e pouca coisa mudou, entendeu? E aí que tinha que ter algum jeito, ou uma conversa, alguma coisa com esse supervisor e falar para ele, "olha, você está disposto a aprender junto com a gente e não só ensinar? Porque se você acha que você sabe tudo, fica difícil". Como ela falou, ela está a dois anos para se aposentar, então, para ela não vai faz̧er diferença. Esse que é o problema (BB, grifos nossos).

Algumas não entenderam muito a ideia, mas nunca rejeitaram nem mandaram o projeto sair ou dispensarem (CB, grifos nossos).

Às vezes ela [supervisora] até dá pra sentir assim "ab, já que eu tenho eles, os pibidianos, não vou nem me esforçar então, é bonito e produtivo, então não vou nem me esforçar pra faz̧er igual eles, vou deixar eles por conta deles, vou continuar do jeito que eu tô"', às vezes parece que é isso, sabe, é estranho (DB, grifos nossos).

De acordo com a Portaria 96/2013³, é dever do supervisor, entre outros aspectos, elaborar, desenvolver e acompanhar as atividades dos bolsistas de iniciação à docência (BRASIL, 2013). Todavia, como podemos observar nos relatos dos participantes, assim como existem professores comprometidos com tal objetivo, existem também aqueles que não se preocupam em atendê-lo, não contribuindo, assim, para o trabalho proposto e desenvolvido no âmbito do Programa por seus participantes. A falta de abertura, de planejamento e de envolvimento dos supervisores para o desenvolvimento das atividades são alguns dos aspectos apontados como limitantes pelos bolsistas de iniciação à docência dos

\footnotetext{
${ }^{3}$ Para esta análise, tomamos como base, também, as Portarias que normatizaram e regularam o Programa no período de coleta dos dados: Portaria Normativa n ${ }^{\circ}$ 260/2010 e Portaria Normativa no 096/2013. É importante ressaltar, todavia, que os objetivos e características do PIBID presentes nessas portarias tomavam como base o Decreto $n^{\circ} 7.219 / 2010$, que dispõe sobre o PIBID, ainda em vigor. Muitos dos dispositivos desses documentos continuam presentes na atual Portaria que dispõe sobre o PIBID e sobre o programa de Residência Pedagógica (Portaria Gab nº 45, de 12 de março de 2018).
} 
subprojetos analisados, os quais atuam diretamente com esses professores nas escolas e dependem de seu acompanhamento e coorientação - aliada à orientação dos coordenadores de área e colaboradores da universidade - para sua inserção no contexto escolar e para a compreensão desse contexto também em sua dimensão prática.

Ainda segundo relatos de alguns bolsistas de iniciação à docência, alguns professores supervisores não têm contribuído com o direcionamento das atividades que deveriam ser realizadas na escola e, como consequência, têm desmotivado alguns estudantes em seu processo de inserção nesse contexto:

E tem a escola que a gente vai lá uma vez por semana, mas o mais instável que eu diria é ir na escola, que você chega lá, eu pelo menos chego na minha escola e nunca sei o que eu vou fazer, tem sempre uma novidade, chega lá e a professora fala "hoje você vai fazer isso, hoje vai fazer isso" ou às vezes nem tem o que fazer. Porque parece que atrapalha, não sei. Às vezes a turma tem prova, aí acontece da professora... não tem como a gente estar em sala, então ela dá outra. / / A professora não sabe como ela vai atender os dois ao mesmo tempo, a sala de aula dela e os alunos do PIBID. As vezes tem esse problema. [...] às vežes a gente chega lá e ela ainda não conseguiu lidar com a situação de sempre ter um norte pra gente, às vezes a gente mesmo tem que dar uma sugestão, alguma coisa assim. [...] Sinceramente eu não tenho mais vontade de ir pra escola [...] A gente sabe que o objetivo do professor era que a gente ficasse na escola, que tivesse pra acompanhar o ritmo da escola, mas assim pra mim que não está funcionando isso (DB grifos nossos).

Olha, eu acho assim, primeiro, na minha opinião, o nosso colégio, o professor só vai na terçafeira de manhã. Eu acho que... tudo bem, a gente está vendo, está conhecendo como é a rotina da sala de aula, só que, sinceramente, para mim não tem acrescentado nada, eu simplesmente chego lá, sento na carteira e fico vendo ele dar aula, entende? A gente não sabe preencher diário, não sabe elaborar plano de aula... não sabe assim, não aprendeu com o PIBID, só se for atrás mesmo, entendeu? Não tem realmente uma participação efetiva, pelo menos no nosso grupo, no nosso colégio. A aula prática que a gente fez foi uma só. E eu vejo também que não é porque o professor não quer, porque ele tem que dar uma matéria em duas aulas semanais. Eu acho pouco demais... Aí, imagina entrar seis alunos numa sala um pouco maior que essa, que já tem quase 40 estudando lá, sabe? Falta espaço físico, fica muito tumultuado, porque não tem outro dia para dividir. É muito aluno fazendo nada, sinceramente, porque o que a gente faz lá é sentar e ficar vendo ele dar aula. Eu acho que a gente devia... sei lá, sabe, ter mais projeto, ter mais coisa. Mas ai também é inviável pelo tempo que ele tem lá. Aí fica difíill, não sei (BB, grifos nossos).

Como podemos observar, a ausência de uma orientação mais direcionada pode afetar, ao mesmo tempo, a formação dos alunos bolsistas, a prática dos professores supervisores e a integração entre a universidade e a escola. Entretanto, como apontado no último relato, o fato de alguns professores supervisores não se envolverem com as atividades do PIBID e não atuarem efetivamente em seu acompanhamento nas escolas pode estar associado, também, às condições em que tais atividades se desenvolvem. De fato, integrar de uma só vez 6 estudantes - ou mesmo 4 - em uma única sala de aula onde há cerca de 40 alunos - não parece ser fácil, tampouco coerente aos professores supervisores e às escolas. Considerando que os professores supervisores possuem mais de uma turma - geralmente várias turmas - e mais de uma aula por semana na mesma escola, seria interessante que os bolsistas de iniciação à docência fossem separados individualmente ou em duplas para seu acesso à sala de aula e para o desenvolvimento das atividades com os professores e suas turmas. Dessa forma, os supervisores teriam a oportunidade de trabalhar com os alunos bolsistas em mais de uma turma e, em contrapartida, os bolsistas teriam contato com mais de um contexto formativo, o que poderia contribuir tanto para sua formação quanto para a formação e a atuação prática dos professores em sala de aula.

Além das limitações apontadas, outro aspecto parece preocupar os participantes dos subprojetos, especialmente os alunos bolsistas: o fato de algumas escolas e professores supervisores (que já atuaram ou que ainda atuam no Programa) considerá-los como "auxiliares" ou "professores substitutos" quando da ausência dos professores regentes de turma. De acordo com a coordenadora do subprojeto A, em certa ocasião foi necessário retirar alunos bolsistas de uma das escolas parceiras por esse motivo: "Tivemos alunos do PIBID, numa escola que eu tive que tirar eles de lá quando eu entrei, que o diretor estava perseguindo os alunos, querendo usar eles como mão de obra para fazer trabalhos dentro da escola. E eu tive que 
interferir e tirar os alunos de lá" (ACA). Relatos de uma das coordenadoras de gestão entrevistadas e de bolsistas de iniciação à docência dos demais subprojetos analisados também evidenciam essa prática em algumas escolas:

Nas escolas, que a gente vê como grande dificuldade? As escolas, que, embora o projeto já exista com um tempo, eles ainda encaram o aluno do PIBID como estagiário. O próprio supervisor. [...] Uma vez a gente foi lá pra explicar o projeto pro diretor, tal. Mas foi meio infeliz, assim, a situação. Porque, no final da conversa, o diretor falou assim, "Então, é bom saber que vai ter esse projeto, porque vocês são da área de [conteúdo específico], e podem levar os reagentes vencidos pra lá, pra vocês descartarem num lugar adequado". Já teve gente, já teve escola, que ligou aqui, pra gente, e falou assim, "Pois é, a professora tal tem dois ajudantes na sala dela. Não tem como vocês mandarem dois, assim, pra mim, pra me dar uma ajuda, também? Essa semana nós vamos ter capacitação, a gente queria uns estagiários, não tem como mandar uns estagiários?". Eu falei, "Olha, escuta, você ligou pro lugar errado. Nós não temos estagiário. Nós somos um programa chamado PIBID, que é muito diferente de um estagiário". "Ué, mas a professora fulana tem!". "Não, ela tem alunos do programa. Não funciona dessa forma" (CG, grifos nossos).

$\mathrm{Na}$ [escola] acontecia, tinha uma professora que estava grávida que faltava muito, às vezes passava mal e acontecia da gente ir pra sala, só nós (CB, grifos nossos).

Já assumimos a sala sozinhos, duas vezes. A primeira oficina que a gente foi, a professora tinha uma reunião da Prova Brasil, aí ficou só nós três na sala as cinco aulas. E daí na outra semana eu faltei, estava doente, alguma coisa, ficou só a Joaquina. Outra vez ela acabou dando as aulas no lugar da professora, porque a professora ficou doente (DB, grifos nossos).

Ela pegou, me deu o livro na mão, tipo, faria 10 minutos depois, eu cheguei, faltava tipo 10 minutos para a aula começar, ai ela simplesmente pegou, deu o livro na minha mão, falou assim, "oh, você vai explicar essa matéria". Eu nunca me senti tão mal em toda a minha vida. Porque, assim, primeiro que o aluno vê que você está ali nervoso, porque você não está preparado, segundo que eu acho ridículo você mandar o aluno abrir o livro e ficar lendo. Sabe, você ficar lendo ali porque eu não tinha contato com aquele livro, mal tinha, a gente não tinha o livro, não tinha preparado aula. [...] Aí depois, nas outras duas turmas era resolver exercício de [conteúdo específico B], aí a gente ficou resolvendo. Mas olha, naquele colégio eu já tive problema de ter que aplicar prova sozinha também e o aluno colar na minha cara e eu falar que eu ia tomar a prova dele e ele falar que eu não tinha prova de que ele estava colando. Então, assim, várias vezes, duas, três vezes eu já fiquei sozinha com o Pedro, já fiquei sozinha com o Gilberto, já fiquei sozinha, sozinha mesmo. Então é difícil. Não é uma situação agradável nem para os alunos e nem para você. Mas ela [professora supervisora] saiu por causa disso... É, um dos motivos (BB, grifos nossos).

No subprojeto B, os bolsistas foram, por um breve período, responsáveis, também, pelo "sexto horário", uma aula-extra oferecida pela escola aos alunos que apresentavam algum tipo de dificuldade nas disciplinas do currículo: "Tinha o sexto horário, que era só uma aula de reforço para os alunos que não entendiam muito bem a matéria em sala de aula. Quem era responsável pelo sexto horário éramos nós do PIBID, então o professor não precisava estar em sala de aula" (BB, grifos nossos).

Assim, vemos que em muitas situações os bolsistas de iniciação à docência foram tratados como auxiliares ou professores substitutos tanto por alguns dos supervisores quanto por professores, coordenadores e gestores das escolas. Em algumas situações, ainda, outros alunos relataram já terem realizado trabalhos e funções que caberiam apenas ao professor supervisor, como é possível observar nas narrativas abaixo:

Os professores supervisores podem combinar com a gente pra gente elaborar uma aula, mas não falar assim "você define". Eles pedem "olha, você tem disponibilidade pra elaborar uma aula pra próxima semana, por exemplo, mês que vem?” Beleza, com o professor dentro de sala de aula a gente vai lá e aplica uma aula, mas não nesse estilo de "a próxima aula é de vocês, façam uma coisa ai" e deixar... Elaborar uma aula está dentro do projeto, mas sempre com o professor auxiliando, não passando a responsabilidade pra nossa mão. Esse é um problema que nós enfrentamos com a nossa última professora supervisora que, como ela estava muito atarefada às vezes ela falava "ah, vou me sentar aqui e você pode assumir a aula”. Então, assim é algo complicado que às vezes nós temos que voltar à nossa coordenação 
aqui e conversar sobre isso, falar assim “oh, professora, não está dando certo e nós gostaríamos que você conversasse lá com o professor”. Então são coisas que é passível que aconteça. Tanto é que foi decidido que mudasse de local, de escola (CB, grifos nossos).

Eu já fiquei na biblioteca várias vezes no horário que era para eu estar em sala de aula, porque passou da atividade, a professora foi para a sala dar aula, mas eu não terminei de corrigir os trabalhos que ela me pediu para corrigir, en fico na biblioteca corrigindo, "então, quando você terminar, você vai lá na sala". Fiquei lá corrigindo um monte de trabalbo, na hora que eu estava voltando para sala, minha colega do PIBID falou, "guarda esses trabalhos, porque se o diretor vê você com trabalho da professora na mão, ele vai brigar com ela, porque você não deveria estar corrigindo isso. Guarda na sua bolsa, esconde" (BB, grifos nossos).

Não entrei em sala, ainda. A única coisa que eu fir foi corrigir uns trabalbinhos e essa semana elaborar uma lista (DB, grifos nossos).

Certamente, o processo de discussão de atividades e de métodos avaliativos faz parte, entre tantos outros aspectos, do processo de formação docente, uma vez que está relacionado aos saberes e à prática da profissão. Todavia, supõe-se que, em se tratando de um programa de formação e de iniciação à docência, os estudantes devessem receber, pelo contato com professores experientes, uma formação orientada e direcionada sobre esse e os demais conhecimentos que constituem o saber fazer docente e que estão articulados aos conhecimentos que também recebem na universidade. E, a partir dos relatos, podemos considerar que tal orientação não tem ocorrido no desenvolvimento de algumas atividades.

Quando esses estudantes, depois de um processo de orientação e planejamento, desenvolvem algum tipo de intervenção supervisionada em sala de aula, é de se esperar que utilizem algum método de avaliação para saber o quanto e como os alunos que participaram dessa intervenção se apropriaram dos conhecimentos discutidos e trabalhados. Neste caso, parece fazer sentido que os bolsistas, numa discussão prévia com os professores orientadores, avaliem a atividade, a fim de que também possam analisar sua própria prática. Tal direcionamento, aliás, está contemplado no texto do Projeto Institucional do PIBID da Universidade, segundo o qual os bolsistas de iniciação à docência, em discussão com o coordenador de área e supervisor, deverão participar do preparo de questões e/ou de diversos tipos de avaliação, a fim de que possam conhecer e analisar as diferentes formas de avaliação que podem ser empregadas, seus pontos positivos e negativos, os cuidados que devem ser dispensados no preparo das questões, bem como a importância de se utilizarem diferentes mecanismos de avaliação e de oferecer um retorno sobre a aprendizagem dos alunos. Trata-se, pois, de atividades inerentes ao ensino e, como tal, devem fazer parte do processo de aprendizagem profissional da docência.

Todavia, não parece coerente que esses mesmos bolsistas avaliem, sozinhos, as atividades desenvolvidas em sala de aula pelos professores supervisores, especialmente nos casos em que não há nenhum tipo de orientação prévia. Neste caso, os licenciandos, exercendo funções e responsabilidades próprias de um professor regente, tornam-se apenas seus "auxiliares". Este não parece ser o objetivo do Programa, ao menos em termos formais. De acordo com a Portaria $n^{\circ} 96 / 2013$, artigo $43^{\circ}$, parágrafo único (BRASIL, 2013b, s/p): "É vedado ao bolsista de iniciação à docência assumir a rotina de atribuições dos docentes da escola ou atividades de suporte administrativo ou operacional"4.

É preciso, portanto, que todos os que se encontram envolvidos no PIBID considerem o contato dos alunos bolsistas com a prática da profissão como um momento de formação, e não como um ingresso precoce à carreira docente, com todas as suas responsabilidades e atribuições. Com a segunda postura, a ideia de iniciação à docência e de "terceiro espaço de formação" (ZEICHNER, 2010)

\footnotetext{
4 Tal disposição é formalizada apenas na Portaria no 96/2013, não constando no texto da Portaria no $260 / 2010$. Todavia, a Portaria $n^{\circ}$ 260/2010 também estabelece, no item 8.3.1., inciso III, que cabe ao supervisor "acompanhar as atividades presenciais dos bolsistas de iniciação à docência sob sua orientação, em conformidade com o PIBID”. Além disso, o Termo de compromisso do bolsista de iniciação à docência, baseado nessa mesma Portaria, estabelece em sua cláusula terceira, inciso XIV: "ao bolsista de iniciação à docência está vetada a prática de regência como parte das atividades do programa”. Todavia, a despeito dessas orientações, foram evidenciados alguns casos de alunos que assumiam nas escolas parceiras do PIBID atividades e responsabilidades de regência, o que levou a CAPES a incluir essa determinação de maneira explícita na nova Portaria $n^{\circ}$ 96/2013. Essa mesma exigência está presente na Portaria Gab nº 45/2018, Art. 20.
}

Educação em Revista|Belo Horizonte|v.36|e222648|2020 
perderá o seu sentido. Concordamos com Tardif (2012) quando ele argumenta sobre a necessidade do reconhecimento da prática da profissão como processo de aprendizagem profissional, a qual deve incluir o desenvolvimento de uma parceria com os professores, de modo que estes também tomem parte na formação dos futuros professores. Tomar parte, todavia, não significa atribuir a eles as responsabilidades de um professor em exercício, mas lhes oferecer o suporte necessário para que possam, gradual e progressivamente, por meio da troca de ideias, do confronto de pontos de vista e do trabalho colaborativo, compreender e analisar a realidade escolar em suas diferentes dimensões, bem como as condições sociais e históricas que geram e são geradas por essa realidade. Afinal, como afirma França (2006), sem a participação efetiva dos professores no processo de inserção dos licenciandos no contexto e nas práticas escolares, corre-se o risco de lhes deixar a tarefa de, sozinhos, estabelecerem as relações e conexões entre o conhecimento e a sua futura prática profissional, o que, como já discutimos, vai contra os princípios formais apresentados pelo PIBID.

Não estamos com isso reproduzindo a ideia que, segundo Freitas (2007), tem sido talvez inconscientemente adotada pelas universidades: que os sistemas de ensino podem se responsabilizar pela formação inicial de seus professores, com o envolvimento de seus "especialistas", que são, antes de tudo, professores. Pelo contrário, defendemos o papel e a importância da universidade como locus de formação docente e, com a mesma intensidade, a necessidade de uma parceria entre essas instituições e as escolas de educação básica para o desenvolvimento dessa formação, tendo em vista a superação da dicotomia ainda existente em muitos cursos de formação inicial entre os conhecimentos teóricos e práticos da profissão. Assim, como já discutimos anteriormente, não se trata de dar maior ênfase à teoria ou à prática na formação do professor, como se fossem elementos dissociáveis. Antes de tudo, trata-se de reconhecer que os saberes acadêmico-científicos e os saberes da experiência se apresentam como diferentes etapas de um mesmo processo de aprendizagem docente e que são, portanto, igualmente importantes e necessários à formação do educador.

Todavia, essa formação prática deve ocorrer de uma forma orientada. É justamente com esse pensamento que alguns dos licenciandos relataram aceitar participar do PIBID. Quando questionados sobre o porquê de terem ingressado no Programa, os bolsistas entrevistados apresentaram diferentes razões, dentre as quais podemos destacar: pela bolsa; pelo enriquecimento do currículo; pela oportunidade de desenvolvimento de pesquisa; por ajudar na preparação para o estágio; por proporcionar o contato com a escola, entre outros aspectos. Entre os motivos apontados, está o fato de o Programa proporcionar o acompanhamento de profissionais já experientes (da universidade e da escola) para o contato com a realidade escolar:

\footnotetext{
Pra mim foi mais essa ideia assim de que en queria, numa etapa do curso, em algum momento do curso fazer uma intervenção em sala de aula, mas acompanhado dos professores aqui da universidade e com um professor do colégio também. Porque pra quem dá aula no PSS [processo seletivo simplificado] ou pegar aula no cursinho, você dá sua aula, mas você não... muitas vezes você não tem aquele planejamento antes de pensar na intervenção que você vai fazer, de elaborar, de discutir com os colegas. Às vezes é só sua ideia lá e pronto. E no PIBID é a ideia de ter um grupo de três ou dois... três pessoas com você. É legal pra você discutir, trocar ideia, ver qual é o ponto interessante (AB, grifos nossos).
}

Não tem que assumir uma turma já, a gente pode estar atuando junto com o professor, mas não precisa estar dominando a turma sozinho ali... a gente vai chegar lá um dia! A gente está aprendendo, porque tem gente que sair da faculdade e já vai, ou antes mesmo antes de terminar a faculdade já vai assumir uma turma! É um choque! (CB, grifos nossos).

Essa mesma preocupação foi apontada nas pesquisas de Carvalho (2013), Moura (2013) e Gatti et al. (2014), nas quais os bolsistas de iniciação à docência participantes relataram se sentir mais seguros em sua inserção nas escolas tendo a orientação dos professores da educação e da universidade. De acordo com Moura (2013), a partir de uma ação orientada, os estudantes sentem-se mais confiantes para desempenharem suas funções e enfrentarem os desafios que surgem durante sua trajetória no Programa.

Como é possível observar nessas pesquisas e nos relatos aqui apresentados, o fato de o PIBID ter como objetivo a inserção do estudante em formação no contexto escolar pelo intermédio, 
observação, acompanhamento e direcionamento de professores em exercício proporciona maior segurança aos licenciandos bolsistas e, da mesma forma, favorece a atuação desses professores como coformadores dos estudantes em seu processo de inserção no cotidiano escolar. Nesse processo, o acompanhamento e a orientação de professores experientes tornam-se fundamentais na complementação do processo de formação profissional.

Como afirma Tardif (2012), o relacionamento dos jovens professores - ou, neste caso particular, de estudantes de licenciatura - com professores experientes é uma situação que permite objetivar os saberes da experiência. Em tal situação, o professor experiente é levado a tomar consciência de seus próprios saberes experienciais a fim de que se torne não apenas um prático, mas, também, um formador. Por isso há a necessidade de que o objetivo relacionado à atuação do supervisor como coformador dos licenciandos no momento de seu contato com a escola esteja presente em todos os projetos e subprojetos não apenas em termos formais - como foi possível de ser observado nos textos do projeto institucional e dos subprojetos analisados - mas, igualmente, na prática.

\section{CONSIDERAÇÕES FINAIS}

A partir do estudo realizado, foi possível observar que a formação e a prática de alguns dos professores supervisores da educação básica têm sido favorecidas e enriquecidas por sua participação no PIBID. Por meio dela, esses professores têm a oportunidade de analisar, ampliar e modificar as práticas que desenvolvem na educação básica a partir do que observam, vivenciam e discutem nos momentos de planejamento das atividades teórico-práticas na universidade e na escola. Tal contribuição favorece, da mesma forma, a aproximação desses professores com a universidade e desta com a escola e seus profissionais, numa perspectiva de formação recíproca, colaborativa e contínua que pode possibilitar, como consequência, intervenções na própria prática educativa.

Todavia, se por um lado existem professores que tomam o PIBID como espaço de formação e de realização de um trabalho colaborativo que contribui, ao mesmo tempo, para o seu desenvolvimento profissional e para a aprendizagem dos estudantes da licenciatura, por outro existem também aqueles que não se comprometem com os objetivos do Programa, não o consideram como espaço formativo e de análise das práticas realizadas, tampouco contribuem para o desenvolvimento de um trabalho colaborativo com a universidade ou para a formação dos bolsistas por eles supervisionados nas escolas.

Tal aspecto pôde ser evidenciado nas narrativas de muitos dos participantes deste estudo, segundo os quais, em alguns dos professores supervisores - que já atuaram ou que ainda atuam no PIBID -, não há uma intencionalidade e direcionamento nas ações realizadas no Programa, o que, de certa forma, compromete o planejamento e desenvolvimento das atividades, a análise das práticas e, mais especificamente, a formação dos bolsistas de iniciação à docência. Segundo esses participantes, alguns professores supervisores e escolas parceiras consideram os alunos bolsistas apenas como auxiliares e, em alguns casos, como professores substitutos, o que contraria o modelo de formação proposto pelo Programa - uma formação orientada, acompanhada, supervisionada, que proporcione, de maneira gradual e contínua, a integração e a inserção dos estudantes da licenciatura nas escolas de educação básica.

Todavia, se é verdade que o PIBID depende da atuação dos professores supervisores como coformadores e coprotagonistas - juntamente com os professores coordenadores e colaboradores - no momento de planejamento, desenvolvimento e avaliação das atividades de iniciação e de formação para a docência, também é fato que a maioria desses professores se encontra muitas vezes em situações de trabalho desfavoráveis, que dificultam uma atuação de maneira satisfatória. Sobre esse aspecto, a análise dos dados permitiu-nos observar que muitos dos supervisores, incluindo-se aqueles que, segundo os participantes entrevistados, se apresentam comprometidos com os objetivos de formação do PIBID, trabalham em tempo integral - muitas vezes em mais de uma escola -, com pouco tempo para o planejamento de suas atividades. Esse fator, de certa forma, pode prejudicar sua participação de maneira mais diretiva na orientação dos alunos da licenciatura e nas atividades relacionadas ao PIBID. Assim, fazse necessário que tais questões sejam ponderadas no momento de avaliação do Programa e da participação dos que nele se encontram envolvidos, a fim de que não nos percamos na ingenuidade de 
responsabilizar ou culpabilizar apenas os professores da educação básica pelo sucesso ou fracasso do processo de integração dos bolsistas de iniciação à docência no contexto escolar.

Além disso, é preciso, antes de tudo, evidenciar a relação que os professores em exercício estabelecem com a ação de orientação dos estudantes da licenciatura nas escolas (FRANÇA, 2006). Precisamos nos questionar: qual o papel dos professores supervisores no processo de formação desses estudantes? Qual o seu limite de atuação nesse processo? Os professores estão preparados para desempenhar mais uma tarefa em meio a tantas outras atividades que lhe são designadas cotidianamente? Esses professores possuem condições satisfatórias para receber bolsistas de iniciação à docência em suas salas de aula? E para atuarem como coformadores em seu processo de iniciação à docência? Possuem formação para exercer essa função? Existe incentivo, valorização e oficialização por parte das redes de ensino para que esses professores possam aceitar e incorporar essa responsabilidade no âmbito de sua carreira profissional? Tais questões indicam, de maneira clara, a necessidade de um aprofundamento sobre a discussão, tendo também como referência a atuação dos professores em exercício, que recebem, acompanham e orientam os licenciandos em suas atividades de inserção nas escolas, enfrentando, muitas vezes, desafios e limitações na realização dessa tarefa.

Outrossim, é preciso considerar o fato de que as escolas e seus professores têm sido responsabilizados pela formação prática dos futuros professores sem que tenham tido a oportunidade de discutir essa questão de forma abrangente. Até então, os professores da educação básica não tinham reconhecimento de sua participação efetiva nesse processo de formação; seu papel se restringia, na maioria dos casos, em ceder o espaço da sua sala de aula para os estagiários para que ali pudessem fazer suas observações e dar sua aula de regência, em cumprimento às exigências do curso de formação. Com o PIBID, é solicitado que eles compartilhem o processo formativo dos futuros professores sem que ao menos tenham sido ouvidos nesse processo e sem que haja, em alguns casos, formação e maiores esclarecimentos a esse respeito.

Por esse motivo, são necessárias ações formativas para que os professores compreendam e possam atuar de maneira efetiva como coformadores de futuros professores em suas primeiras inserções nas escolas. Trata-se, portanto, da necessidade de se consolidar, no âmbito do Programa e por meio da parceria entre escolas e universidades, ações de "formação de formadores", nas quais membros internos e externos ao Programa - supervisores, coordenadores de área, colaboradores, coordenadores de gestão e institucional, núcleos regionais, secretarias de ensino e equipes gestoras das escolas - estivessem envolvidos. Tais ações contribuiriam não apenas para uma melhor definição sobre o papel dos supervisores e dos demais sujeitos no Programa, mas, igualmente, para uma melhor atuação desses profissionais no processo de formação dos licenciandos.

Igualmente, é necessário que as redes de ensino e, mais especificamente, o poder público adotem o PIBID não apenas como mais um programa pontual, de governo, mas como uma política abrangente, de Estado, voltada à formação docente, garantindo as condições necessárias de trabalho e de carreira que permitam a esses profissionais destinar parte de sua atividade profissional para essa tarefa particularmente importante na formação prática dos futuros professores. Precisamos levar em consideração todos esses aspectos, afinal, pensar em uma política de formação implica pensar, com a mesma seriedade, nas condições objetivas para que tal formação se materialize no âmbito da prática. Transferir à escola e aos seus profissionais responsabilidades na formação de futuros professores sem que essas condições sejam garantidas, e sem que as relações entre o ensino superior e a educação básica sejam de fato estabelecidas, pode se configurar como mais um fator limitante a ser enfrentado no processo formativo.

\section{REFERÊNCIAS}

AFONSO, Andréia Francisco. Os professores da escola de educaşão básica e suas contribuições na formação dos bolsistas de iniciação à docência da área de Química. 161f. Tese (Doutorado em Ciências) - Programa de PósGraduação em Química. Universidade Federal de São Carlos, São Carlos, 2013. 
BRASIL. Coordenação de Aperfeiçoamento de Pessoal de Nível Superior. Portaria nº 096, de 18 de julho de 2013. Regulamenta o Programa Institucional de Bolsa de Iniciação à Docência (PIBID). Brasília, DF, 2013.

BRASIL. Decreto $n^{0}$ 7.219, de 24 de junho de 2010. Dispõe sobre o Programa Institucional de Bolsa de Iniciação à Docência - PIBID e dá outras providências. Brasília, DF, 2010.

BRASIL. Portaria Gab n 45, de 12 de marco de 2018. Dispõe sobre a concessão de bolsas e o regime de colaboração no Programa de Residência Pedagógica e no Programa Institucional de Bolsa de Iniciação à Docência. SEI/CAPES, 2018.

CARVALHO, M. A de. Um modelo para a interpretação da supervisão no contexto de um subprojeto de Física do PIBID. Tese (Doutorado) - Universidade Estadual de Londrina, Londrina, 2013.

DAMIANI, M. F. Entendendo o trabalho colaborativo em educação e revelando seus benefícios. Educar, Curitiba, n. 31, p. 213-230, 2008. Editora UFPR. Disponível em: http://www.scielo.br/pdf/er/n31/n31a13. Acesso em: 29 jul. 2013.

DORNELES, A. M. A Roda dos Bordados da Formação: o que bordam as professoras de Química nas histórias de sala de aula? Dissertação (Mestrado) - Universidade Federal do Rio Grande do Sul, Porto Alegre, 2011.

FRANÇA, D. de S. Formação de Professores: a parceria escola-universidade e os estágios de ensino. UNIrevista, v. 1, n. 2, abr. 2006.

FREITAS, H. C. L. de. A (nova) política de formação de professores: a prioridade postergada. Educação \& Sociedade. Campinas, v. 28, n. 100, out. 2007.

GAFFURI, P. Rupturas e continuidades na formação de professores: um olhar para as práticas desenvolvidas por um grupo no contexto do PIBID-Inglês/UEL Dissertação (Mestrado) - Universidade Estadual de Londrina, Londrina, 2012.

GARCÍA, Carlos Marcelo. O professor iniciante, a prática pedagógica e o sentido da experiência. Formação Docente, Belo Horizonte, v. 2, n. 3, p. 11-49, ago./dez. 2010.

GARCÍA, Carlos Marcelo; VAILLANT, Denise. Desarrollo profesional docente. Como se aprende a enseñar? Madrid: Narcea, 2009.

GATTI, B. A. et al. Um estudo avaliativo do Programa Institucional de Bolsa de Iniciação à Docência (PIBID). São Paulo: FCC/SEP, 2014.

LIBÂNEO, José Carlos. As políticas de formação de professores no contexto da reforma universitária: das políticas educativas para as políticas da educação. Revista Profissão Docente, Uberaba, v. 4, n. 12, p. 3355, set./dez. 2005.

LÜDKE, M.; ANDRÉ, M. E. D. A. Pesquisa em educação: abordagens qualitativas. 2 ed. São Paulo: Editora Pedagógica e Universitária, 2013.

MIZUKAMI, Maria da Graça Nicoletti. et al. Escola e aprendiæagem da docência: processos de investigação e formação. São Carlos: EdUFSCar, 2002. 
MOURA, Eliton Meireles de. O programa institucional de bolsa de iniciação à docência PIBID na formação inicial de professores de matemática. 197f. Dissertação (Mestrado em Educação) - Programa de Pós-graduação em Educação. Universidade Federal de Uberlândia, Uberlândia, 2013.

NÓVOA, Antônio. Professores - Imagens do futuro presente. Lisboa: Educa, 2009.

PAREDES, G. G. O. Um estudo sobre o PIBID: saberes em construção na formação de professores de ciências. Dissertação (Mestrado) - Universidade Federal do Paraná, Curitiba, 2012.

REALI, A. M. M. R.; TANCREDI, R. M. S. P. A importância do que aprende na escola: análise de uma experiência de parceria escola-famílias e universidade-escola. Paideia, Ribeirão Preto, SP, v. 15, n. 31, p. 239-247, 2005.

SHULMAN, Lee. Conocimiento y enseñanza: fundamentos de la Nueva reforma. Profesorado. Revista de curriculum y formación del profesorado, v. 9, n. 2, 2005.

STANZANI, E. de L. O papel do PIBID na formação inicial de professores de Química na Universidade Estadual de Londrina. Dissertação (Mestrado) - Universidade Estadual de Londrina, Londrina, 2012.

TARDIF, Maurice. Saberes docentes e formação profissional. 13. ed. Petrópolis, RJ: Vozes, 2012.

ZEICHNER, Ken. M. Repensando as conexões entre a formação na universidade e as experiências de campo na formação de professores em faculdades e universidades. Educação, Santa Maria, v. 35, n. 3, p. 479-504, set./dez. 2010.

Submetido: $12 / 04 / 2019$

Aprovado: 19/08/2019 